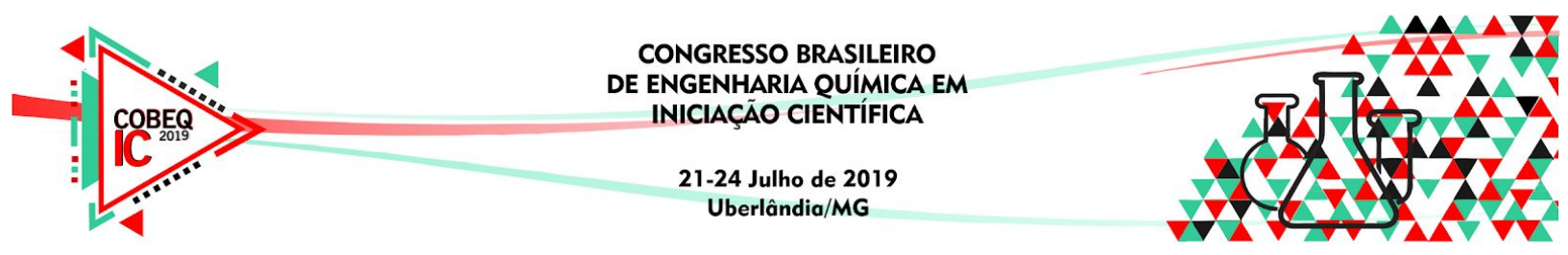

\title{
PERFIL DE ADSORÇÃO DE ÍONS NÍQUEL EM RESINAS CROMATOGRÁFICAS A BASE DE SÍLICA PARA PURIFICAÇÃO DE PROTEÍNAS RECOMBINANTES
}

\author{
R. PAULA ${ }^{1}$, W. KOPP, C. SARGO e R. L. C GIORDANO ${ }^{1}$ \\ ${ }^{1}$ Universidade Federal de São Carlos, Departamento de Engenharia Química \\ E-mail para contato: depaula016@gmail.com
}

\begin{abstract}
Uma das mais importantes contribuições da biotecnologia moderna é a produção de proteínas recombinantes. A inserção da cauda de poli-histidina (poli-his) em proteínas recombinantes, facilita o processo de purificação através da afinidade da histidina com metais na superfície de resinas cromatográficas. Neste contexto, o objetivo deste trabalho foi avaliar o processo de adsorção de íons níquel em sílica produzida nacionalmente e ativada com grupos IDA, para purificação de proteínas recombinantes. Nesta etapa do estudo, foi construída uma curva de calibração para quantificação de níquel em solução, permitindo avaliar a concentração desse íon metálico adsorvido à resina cromatográfica. $\mathrm{O}$ complexo níquel-IDA também foi avaliado quanto a sua estabilidade em condições comuns a processos de purificação, apresentando ótimos resultados. Nestes experimentos os íons níquel mantiveram-se adsorvidos na coluna, mesmo após testes de dessorção com altas concentrações de imidazol. A resina PY-IDA adsorveu 82,96 $( \pm 16,58) \mathrm{mMols}$ de níquel por grama de sílica ativada (PY-IDA). Futuros experimentos de purificação de proteínas recombinantes utilizando colunas com o material testado neste trabalho poderão assim ser realizados.
\end{abstract}

\section{INTRODUÇÃO}

Processos de purificação de proteínas tendem a ser complexos, lentos, e com elevado número de etapas, elevando os custos de produção de uma determinada biomolécula (ALTARUGIO, 2014). A incorporação de caudas ("tag") em proteínas recombinantes, permite diminuir tais custos uma vez que reduz o número de etapas necessárias para purificação custo-efetiva (AQUINO, 2004). Os resíduos de histidina presentes na superfície de proteínas (de 6 a 10 em proteínas recombinantes com cauda de poli-histidina), interagem fortemente com íons de metais bivalentes, na superfície de resinas cromatográficas, permitindo uma purificação seletiva da biomolécula através de uma técnica conhecida como IMAC (Immobilized Metal Ion Affinity Chromatography) (GE HEALTHCARE, 2010). 


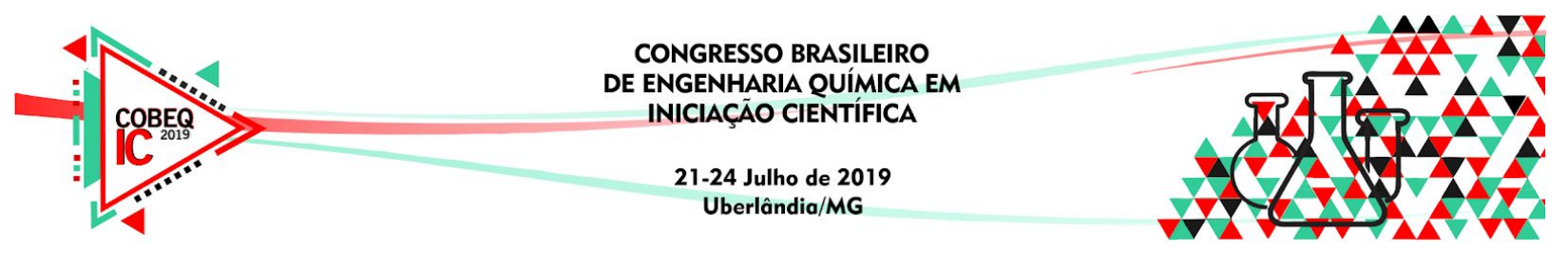

Em IMAC, para redução de custos de produção, muitas vezes são utilizadas resinas a base de sílica. A química de superfície da sílica deve ser modificada para inserção de um agente quelante que formará posteriormente um complexo com o metal bivalente. A escolha do agente quelante é fundamental, uma vez que as propriedades de adsorção do metal, bem como a estabilidade do complexo formado dependerão dele (BRESOLIN et al, 2009). O complexo suporte-metal será mais estável quanto mais polidentado for o agente, porém nestes casos existe uma menor quantidade de sítios disponíveis para ligação com a proteína. $\mathrm{O}$ ácido iminodiacético (IDA) é um agente tridentado (possuindo um átomo de nitrogênio e três de oxigênio para a coordenação), ou seja, quelata o íon metálico que ocupa três sítios de coordenação para formação do complexo, conforme mostra a figura 1 (BRESOLIN et al, 2009).

Figura 1: Agente quelante IDA complexado com íon metálico

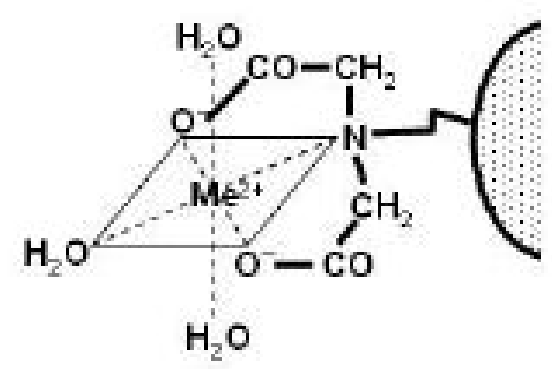

Visando contribuir para o desenvolvimento custo-efetivo de métodos para purificação de proteínas recombinantes, neste trabalho foi investigado o uso de resinas de sílica sintetizadas nacionalmente com grupos IDA (PY IDA) em sua superfície para teste de carregamento de íons níquel. Uma vez construído o sistema de coluna, a técnica IMAC será implementada para purificação de enzimas com cauda de poli-histidina, através da afinidade desta pelos íons do metal.

\section{MATERIAIS E MÉTODOS}

\subsection{Materiais}

Foi utilizado neste trabalho sulfato de níquel da Synth, colunas cromatográficas de 1 $\mathrm{mL}$ preenchidas com o material PY-IDA, sintetizado pela Kopp Technologies e Imidazol da Sigma-Aldrich. Para o carregamento das colunas fez-se uso de bomba peristáltica com vazão controlada. Para construção da curva de calibração e medidas de concentração de níquel, foi utilizado espectrofotômetro SPECORD S6000 da Analytik Jena.

\subsection{Procedimentos Experimentais}

\subsubsection{Construção da Curva de Calibração para Quantificação de Níquel}




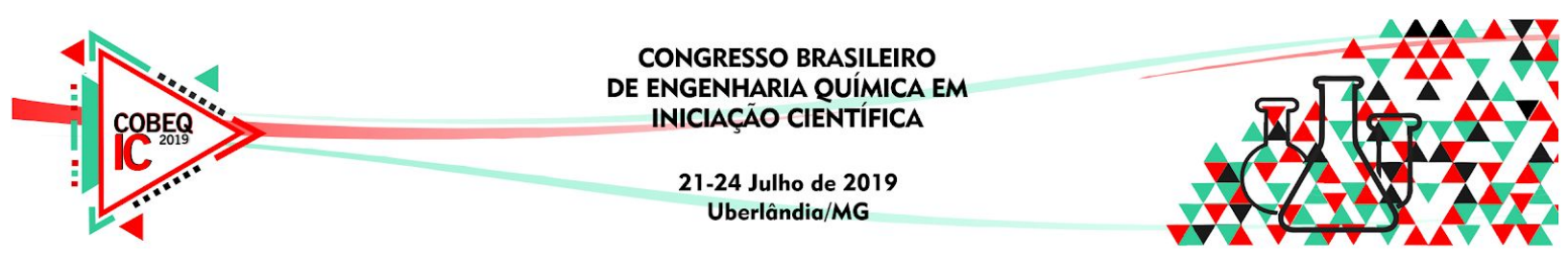

Primeiramente, realizou-se um Scan completo (180-100 nm) em espectrofotômetro de uma solução de sulfato de níquel $25 \mathrm{mM}$, onde identificamos em quais comprimentos de onda poderiam ser observados picos de maior adsorção e seletividade. Em seguida foi construído uma curva de calibração. Foram feitas diluições seriadas na faixa entre 25 a $2.5 \mathrm{mM}$ da solução de sulfato de níquel, as quais foram analisadas no espectrofotômetro nos comprimentos de onda de $395 \mathrm{~nm}$ e $195 \mathrm{~nm}$ (selecionados previamente).

\subsubsection{Carregamento da Coluna com Níquel}

Em colunas cromatográficas de $1 \mathrm{~mL}$, foi adicionado aproximadamente 0.6 gramas do material sintetizado com grupos IDA na superfície (PY-IDA). Após, utilizando a bomba peristáltica iniciou-se o experimento passando água pela coluna a $1 \mathrm{~mL} / \mathrm{min}$, retirando amostras em intervalos de 5 minutos. Prosseguiu-se com a passagem de água pela coluna até que a coluna a atingisse o equilíbrio, ou seja, quando a leitura de absorbância obtida no espectro da amostra retirada fosse ao redor de zero. Em seguida, passou-se pela coluna uma solução de sulfato de níquel $25 \mathrm{mM}$, retirando amostras em intervalos de 1,5 minutos. Este processo foi realizado até a saturação da coluna, ou seja, até que a solução que saísse da coluna estivesse com a mesma concentração de entrada (25 mM do metal). As quantificações de níquel foram realizadas por meio das leituras de absorbância obtidas em espectrofotômetro.

\subsubsection{Estabilidade do Complexo Níquel-IDA}

Após o carregamento das colunas, iniciou-se os procedimento de lavagem e dessorção a fim de verificar a estabilidade do complexo formado entre o material da coluna e os íons níquel. Para isso, iniciando com a etapa de lavagem, foi passado uma solução de água pela coluna, retirando amostras em intervalos de 1,5 minutos até que a leitura de absorbância no espectro fosse ao redor de zero. Seguiu-se então com os testes de estabilidade para avaliar a dessorção indesejada de $\mathrm{Ni}^{2+}$ a partir da coluna utilizando soluções de tampão fosfato $\mathrm{pH} 7.4$ $25 \mathrm{mM}$ acrescida de cloreto de sódio $50 \mathrm{mM}$ e imidazol, em diferentes concentrações (250 $\mathrm{mM}, 500 \mathrm{mM}$ e $1 \mathrm{M}$ ). Passou-se cada solução contendo imidazol por 16 minutos retirando amostras em eppendorfs de $2 \mathrm{~mL}$. As quantificações de níquel foram realizadas por meio das leituras de absorbância obtidas no espectrofotômetro e as equações obtidas na etapa de construção da curva de calibração.

\section{RESULTADOS E DISCUSSÃO}

Iniciando com o método de scan completo para o níquel no espectrofotômetro, foi verificada a presença de picos de absorção de luz na região de $195 \mathrm{~nm}$ e também em $395 \mathrm{~nm}$, conforme apresentado na figura 2 (a). O pico em $195 \mathrm{~nm}$ foi maior do que aquele em $395 \mathrm{~nm}$ pois em comprimentos de onda mais baixos, um maior número de substâncias tendem a absorver luz. Com os comprimentos de onda determinados, foi construída uma curva de calibração para obtenção de uma equação que relacionasse a absorbância obtida pelo equipamento e a concentração de níquel em solução. A figura 2 (b) apresenta esta curva. 


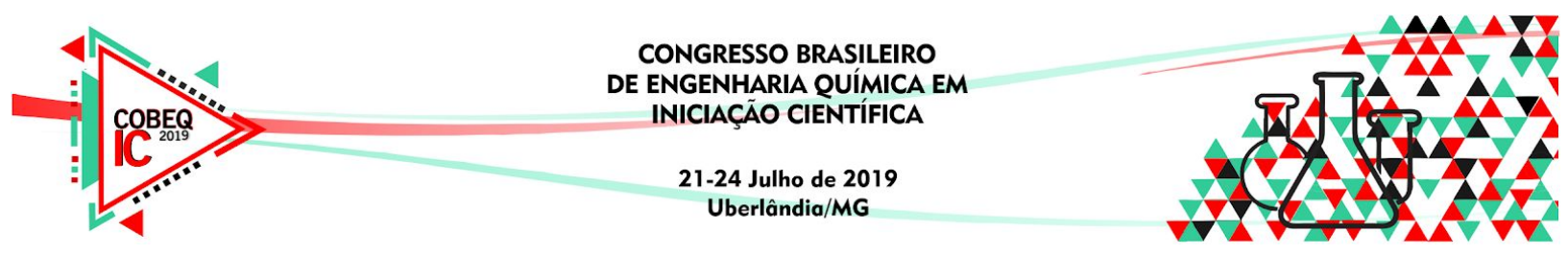

Figura 2 - (a) Scan completo para o sulfato de níquel. / (b) Curva de calibração para o níquel em $395 \mathrm{~nm}$ e $195 \mathrm{~nm}$

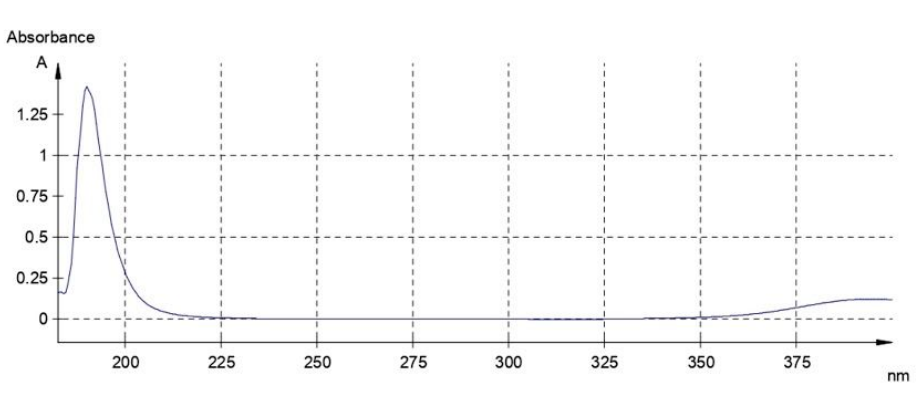

(a)

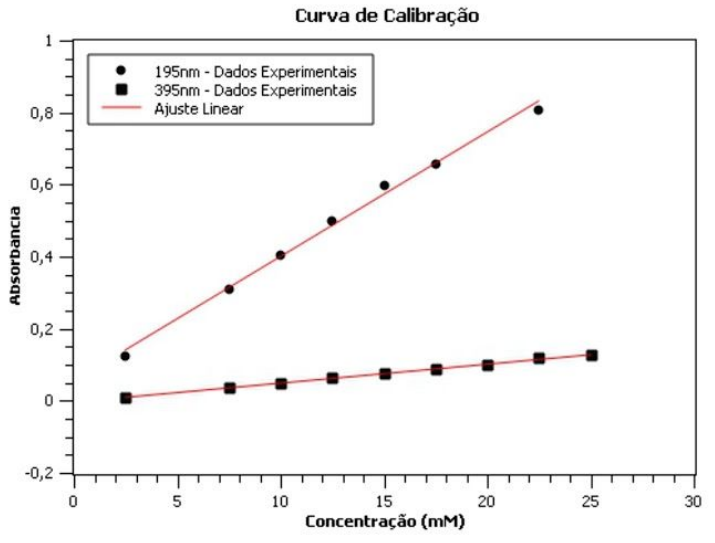

(b)

Para $195 \mathrm{~nm}$ e $395 \mathrm{~nm}$ foram obtidas as equações 1 e 2, respectivamente:

$$
\begin{aligned}
& A b s=0,344 \cdot[\text { Níquel } m M] \\
& A b s=0,0054 \cdot[\text { Níquel } m M]
\end{aligned}
$$

Os ajustes lineares apresentaram um bom coeficiente de determinação de 0,99 , indicando assim que as equações obtidas são satisfatórias para o cálculo da concentração de níquel através da absorbância coletada no espectro. A fim de obter um método mais seletivo para medida de concentração dos íons níquel em solução decidiu-se realizar os testes posteriores apenas em $395 \mathrm{~nm}$ pois, conforme mencionado, um maior número de substâncias absorvem luz em menores comprimentos de onda, o que poderia tornar impreciso os testes em que as medidas fossem realizadas em $195 \mathrm{~nm}$. Com o comprimento de onda (395 nm) e a equação 2 determinados, a quantificação de níquel liberado pela coluna pôde ser realizada. Assim, o carregamento da coluna com os íons níquel está representado na figura 3 (a).

Os dados permitem concluir que após 1 minuto e meio de passagem de solução de sulfato de níquel pela coluna, a mesma já começa a atingir a saturação, ou seja, a coluna passou a liberar íons níquel pois sua capacidade de adsorção havia sido atingida. Em número de mols, a coluna chegou a adsorver 86,92 ( $\pm 3,47)$ mMols de níquel nesta etapa, o que equivale a 86,92 $( \pm 3,47) \mathrm{mMols} / \mathrm{mL}$ de coluna e 144,86 $( \pm 5,77) \mathrm{mMols} / \mathrm{g}$ de material (PY IDA). Esses resultados podem ser considerados muito bons já que a capacidade de adsorção de níquel foi comparável a resultados obtidos para resinas cromatográficas a base de agarose (GE HEALTHCARE, 2010). Verifica-se que após este processo que a coluna adquiriu uma coloração proveniente dos íons níquel adsorvidos, fato que não ocorreria se a sílica utilizada não fosse ativada com os grupos IDA em sua superfície (figura 4). Com isso, foram realizados 


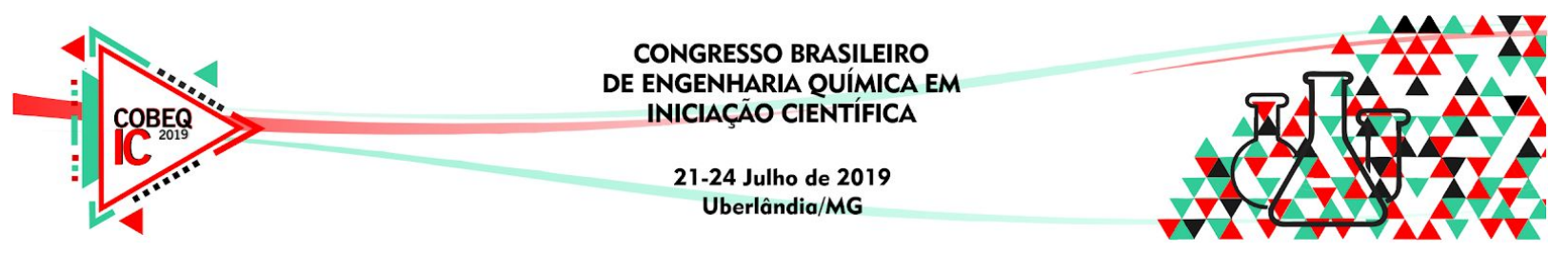

testes com a coluna carregada para verificar a estabilidade do complexo níquel-IDA formado. Tal estabilidade pode ser analisada por meio da passagem pela coluna de soluções com diferentes concentrações de imidazol, conforme apresenta a figura 3 (b).

Figura 3 - (a) Adsorção de níquel em coluna PY IDA. / (b) Lavagem da coluna e dessorção de níquel.

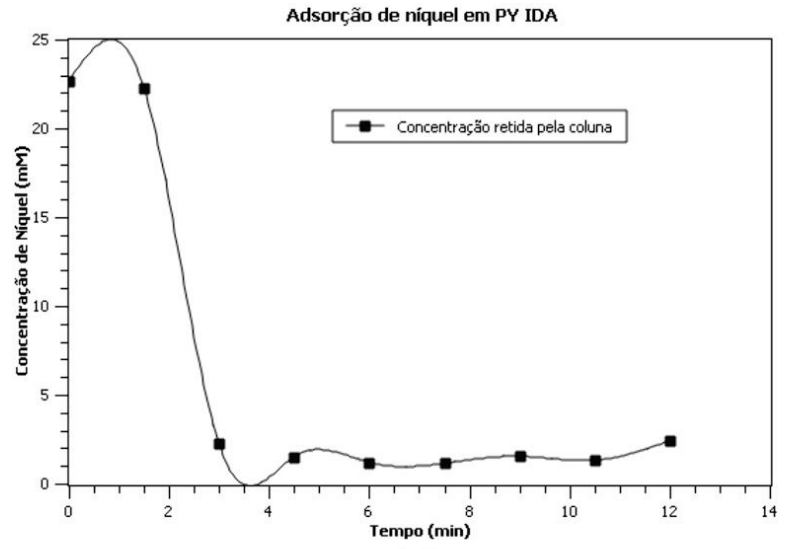

(a)

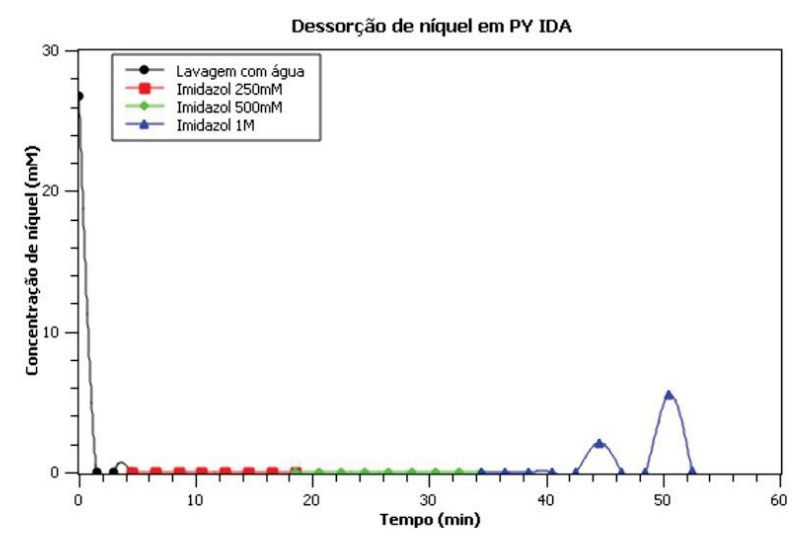

(b)

Figura 4 - À esquerda coluna com material PY-IDA sem o carregamento, à direita após a adsorção com níquel.

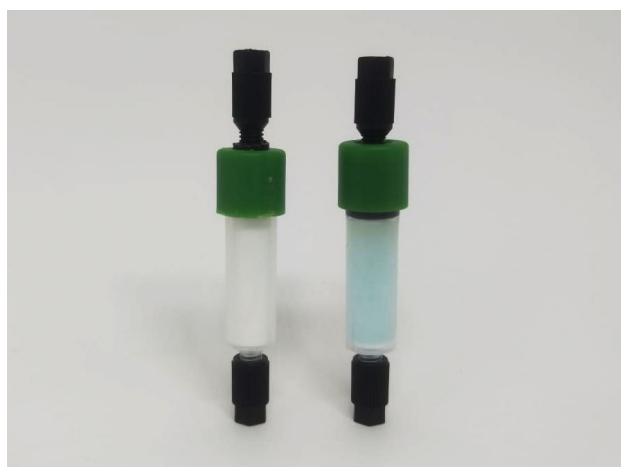

Uma vez que a resina PY IDA apresentou desempenho ótimo na adsorção de íons níquel, avaliamos também a estabilidade da interação IDA-Ni2+ em condições reais de processo de purificação de proteínas. Inicialmente avaliamos a lavagem da coluna através da passagem de água tipo II, foi verificado um pico no gráfico de dessorção proveniente de íons níquel que embora estivessem presentes na coluna, não estavam adsorvidos quimicamente ao material, e assim foram liberados neste primeiro momento. Em número de mols, saíram da coluna 28,70 $( \pm 2,92) \mathrm{mMols}$ de níquel. Em seguida foram passadas pela coluna soluções contendo imidazol nas concentrações de $250 \mathrm{mM}$ e $500 \mathrm{mM}$. O imidazol é comumente empregado para dessorção de proteínas com cauda de poli-his a partir de resinas IMAC. O complexo IDA-níquel formado apresentou excelente estabilidade, já que não foi observado 


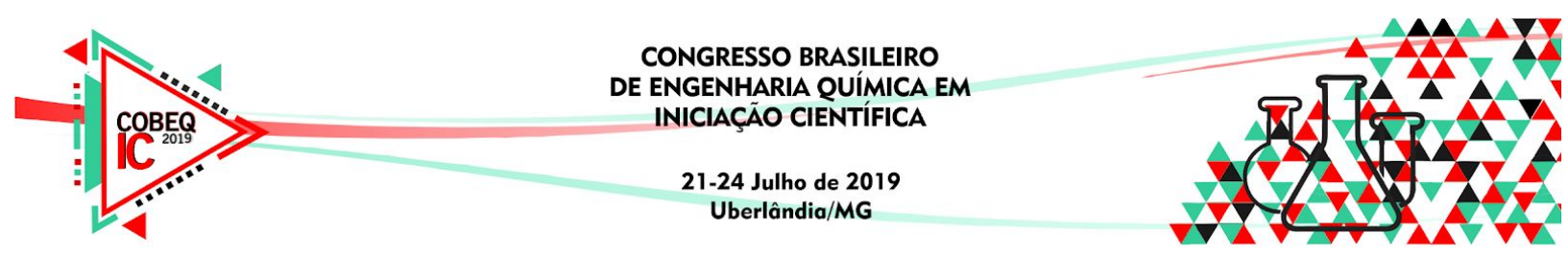

picos de dessorção, ou seja, não houve desprendimento de níquel da coluna nas condições de processo.

Aumentando a concentração de imidazol na solução para $1 \mathrm{M}$, observamos (figura 3(b)) alguns pequenos picos de dessorção de níquel, indicando a liberação de $8,44( \pm 1,78) \mathrm{mMols}$ de níquel da coluna. Desta forma, há indícios de que trabalhar com essa concentração de imidazol poderia trazer problemas em um futuro processo de purificação. Contudo, a literatura indica que processos de purificação de proteínas recombinantes em colunas IMAC utilizam geralmente soluções com até $500 \mathrm{mM}$ de imidazol na dessorção (GE HEALTHCARE, 2010). Assim, observado o bom comportamento do complexo formado na dessorção com até $500 \mathrm{mM}$ de imidazol, a coluna poderá ser testada sem problemas na purificação de proteínas recombinantes. Sabendo o número de mols que adsorveram e dessorveram da coluna durante todas as etapas, têm-se que a coluna manteve adsorvida 82,96 $( \pm 16,58)$ mMols de níquel por grama de sílica ativada (PY-IDA).

\section{CONCLUSÃO}

O material PY-IDA mostrou-se eficaz para ao carregamento de grupos níquel em sua superfície, uma vez que o complexo níquel-IDA formado manteve-se estável em teste de dessorção com solução contendo imidazol até $500 \mathrm{mM}$. Observou-se apenas pequenos picos de dessorção em concentrações extremas de imidazol $(1 \mathrm{M})$, o que não interferiria em um futuro real processo de purificação. Ao final de todo processo, a coluna manteve adsorvida 82,96 ( \pm 16,58) mMols de níquel por grama de sílica ativada (PY-IDA). Assim, testes posteriores de purificação pela técnica IMAC poderão ser realizados utilizando a coluna obtida e enzimas recombinantes com cauda de poli-histidina.

\section{REFERÊNCIAS}

AltarugiO, L. M. Purificação de Penicilina G Acilase produzida por Escherichia coli Megaterium recombinantes. Dissertação de mestrado, Universidade Federal de São Carlos, 2014.

AQUINO, L. C. L. Purificação de pró-insulina humana recombinante com cauda de poli(histidina): cromatografia em membranas de afinidade com íons metálicos imobilizados. Tese de doutorado, Universidade Estadual de Campinas, Novembro de 2004.

BRESOLIN, I. T. L.; MIRANDA, E.A; BUENO, S. M. A. Cromatografia de afinidade por íons metálicos imobilizados (IMAC) de biomoléculas: aspectos fundamentais e aplicações tecnológicas. Quim. Nova, v. 32, p. 1288-1296, 2009.

GE HEALTHCARE. Strategies for Protein Purification: Handbook. Uppsala Sweden: General Electric Company, 2010. 